\title{
Pediatric Otolaryngology Training Program and Surgical Exposure in Western Province, Saudi Arabia; Toward Surgical Competency in Pediatric Otolaryngology
}

\author{
Al-khatib, . $^{1}$ \& Alsheef, H.A. ${ }^{2}$
}

\begin{abstract}
Introduction: King Abdulaziz University, in the Western Province of Saudi Arabia, in collaboration with King Saud Bin Abdulaziz University, has had a pediatric otolaryngology fellowship program in place since 2013, but no clear competency surgical caseload has been identified.

Objective: To review the surgical load at the otolaryngology department in Saudi Arabia and to compare the currently implemented fellowship program with international standards.

Methods: This was a descriptive cross-sectional study performed in King Abdulaziz University (KAU) hospital and King Saud Bin Abdulaziz University hospital. The number of otolaryngology surgeries was collected from the hospitals' medical records for all patients $<18$ years who underwent surgical interventions from 2013 to 2018. The data collected were compared with the accreditation council for graduate medical education (ACGME) international benchmarks.
\end{abstract}

Results: The average annual number of procedures performed versus benchmarks were $10.2 \mathrm{Vs} .20$ for congenital anomalies procedures $(p=0.003), 15.7 \mathrm{Vs}$. 12 for head and neck surgeries $(p=0.231)$, 3.4 Vs. 30 for otology procedures $(p<0.001), 11.8$ Vs. 5 for closed airway procedures for children $<3$ years $(p=0.088), 16.8 \mathrm{Vs} .5$ for endoscopic airway procedures for children $>3$ years $(p<0.001), 9.4 \mathrm{Vs}$. 8 for open airway procedures ( $p=0.439), 172.2$ Vs. 50 for endoscopic interventions $(p=0.006), 34.6$ Vs. 40 for rhinology procedures $(p=0.189)$ and 2.8 Vs. 5 for facial plastic surgeries $(p<0.001)$.

Conclusion: The number of surgical endoscopic airway procedures and head and neck surgeries meets the international benchmarks, whereas procedures of congenital anomalies, otology, rhinology and facial plastics do not meet the international benchmarks within a single year, so a reduction of the two-year fellowship to one year would not be appropriate.

Keywords: Competency, Fellowship, International benchmarks, Pediatric otolaryngology, Training programs, Surgical caseload

\section{Introduction}

Data from the Central Department of Statistics and Information reveals that about half of the Saudi Arabian population are below the age of 29 years (GHD, 2016).

${ }^{1}$ Associate professor, Department of Otolaryngology-Head Neck Surgery, Faculty of Medicine, King Abdulaziz University, Jeddah, Saudi Arabia.

${ }^{2}$ Fellow alumni at King Abdulaziz University, currently a consultant at Children hospital, Dammam, ministry of health, Saudi Arabia.

Corresponding Author: Talal Al-Khatib

Associate Professor \& Consultant, Program director, pediatric Otolaryngology, Department of OtolaryngologyHead \& Neck Surgery, Faculty of Medicine, King Abdulaziz University, PO Box 80215, Jeddah 21589, Saudi Arabia.

Email: talkhatib@kau.edu.sa

DOI: http://doi.org/10.4038/seajme.v14i2 275
The pediatric population below the age of 18 years constitutes $35.8 \%$ of the Saudi Arabia population pyramid (World Bank Statistics, 2018). A considerable proportion of children in the pediatric age group experience diseases that require appropriate otolaryngology evaluation and management (Accreditation Council for Graduate Medical Education, 2013).

The pediatric otolaryngology specialty provides medical as well as surgical care for patients at 18 years of age or younger, presenting with otolaryngologic problem (Accreditation Council for Graduate Medical Education, 2013). A number of complicated conditions, such as congenital anomalies, ear fractures, adenoid diseases, tonsillar abnormalities and sinonasal diseases, require surgical interventions (Tunkel et al., 2017). Therefore, the need for a pediatric

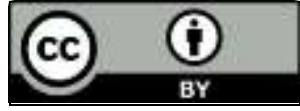


otolaryngology fellowship program was identified, and the health authorities (The Saudi Council for Health Specialties) put in practice a fellowship program, starting in 2013. However, no clear competency surgical caseload was identified, as it was a durationbased framework for fellowships under the umbrella of Saudi commission for health specialties. The program started in the Western Province of Saudi Arabia at King Abdulaziz University, in collaboration with King Saud Bin Abdulaziz University. One year later, the fellowship started in the central region, in a collaboration between King Saud Bin Abdulaziz University and Prince Sultan military hospital in Riyadh.

The fellowship program was implemented in a number of hospitals in Saudi Arabia, but there was no adequate monitoring and regular evaluation of the efficiency and effectiveness of this program (Tunkel et al., 2017). The duration of the fellowship was set at two years but appropriate content, training and surgical exposure were not clearly established as the training system was duration based more than competency based (Tunkel et al., 2017). For the establishment of a successful training program for medical trainees, knowledge of the international curricula benchmarks and comparison of those benchmarks to the program currently in practice is fundamental (Baker et al., 2005; Weaver et al., 2010). Thus, the aim of this study was to review the surgical load at the otolaryngology department in the Western Province in Saudi Arabia, and to compare the local data with the international benchmark standards.

\section{Methods}

This was a descriptive cross-sectional study, carried out in two institutions in the Western Province in Saudi Arabia that were involved in a pediatric otolaryngology fellowship program, i.e., King Abdulaziz University (KAU) hospital and King Saudi Bin Abdulaziz University hospital. Data were collected from the hospitals' medical records at departments of otolaryngology. Medical records included were those for all patients at the studied departments between birth and the age of 18 years who underwent surgical interventions from 2013 to 2018. Three cycles (three fellows) were evaluated (2013-14, 15-16 and 17-18). The data collected were the numbers of patients undergoing surgeries for congenital anomalies, head and neck surgeries, otology surgeries, closed airway procedures, open airway procedures, endoscopic intervention, rhinology surgeries and facial plastic surgeries.

The collected data were organized and interpreted according to the pediatric otolaryngology fellowship program logbook system of the Accreditation Council for Graduate Medical Education (ACGME) (Batalden et al., 2002; The Accreditation Council for Graduate Medical Education and The American Board of Otolaryngology, 2015). The ACGME defines specific curriculum points, objectives and regulations in its document, "Program Requirements for Fellowship Education in Pediatric Otolaryngology" (ACGME, 2020). The ACGME requires pediatric otolaryngology fellows to show competence in diagnosis and management of patients at the age of 18 years or younger with inflammatory disorders, infections, congenital anomalies, communication problems and hearing impairment. They are also required to show competence in performing procedures in certain domains, i.e., congenital anomalies, head and neck, otology, closed airway, open airway, endoscopic intervention, rhinology and facial plastics (ACGME, 2020).

In this study, we compared the number of surgical procedures performed during the period 2013 to 2018 at Western Province hospitals in Saudi Arabia in different surgical domains with the international benchmarks set by the ACGME, and we traced the trend of change in numbers of cases performed annually in each of the studied surgical domains. Ethical approval was obtained from King Abdulaziz University biomedical ethics committee (Reference number 78-18).

\section{Statistical analysis}

All data were fed into the computer and analyzed using the Statistical Package for Social Science (SPSS) software, version 25.0 (Wagner, 2013). The number of cases was presented, grouped by year. Statistical significance was determined at the 0.05 level.

\section{Results}

Table 1 details the numbers of surgical procedures performed in different otolaryngology domains in the studied Western Province hospitals in Saudi Arabia from the years 2013 to 2018. For congenital anomalies procedures, the average number of surgeries carried out from 2013 to 2018 was 10.2 , and this number was significantly lower 
than the benchmark set by ACGME, i.e., 20 $(p=0.003)$ (Table 2). The number of cases performed in each specific cycle did not reach the benchmark in any year from 2013 to 2018
(Figure 1). The highest number of cases was performed during the years 2017 and 2018, when the number was 16 .

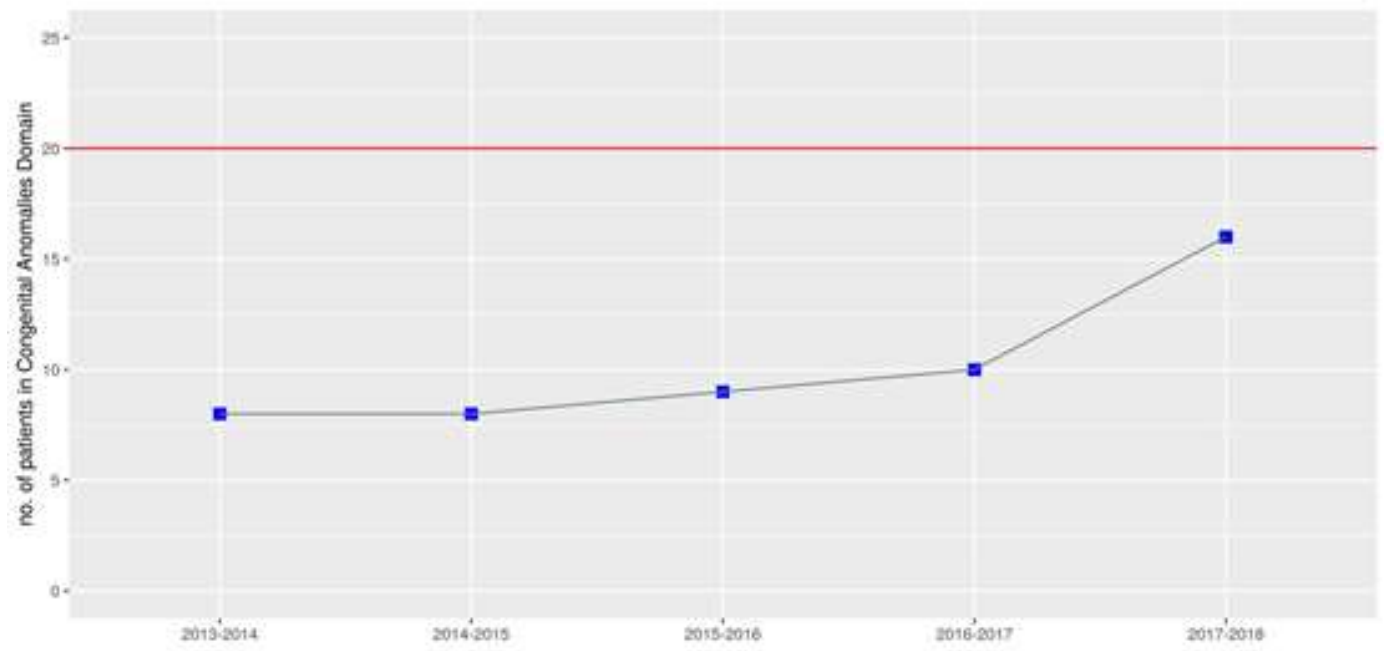

Figure 1: Number of cases performed in congenital anomalies domain during the years 2013 to 2018 in the studied hospitals (blue line and dots) in comparison to the international benchmark (red line)

To assess if there is a significant upward or downward trend in the number of procedures performed, we conducted a regression of counts on time, and though the numbers of cases increased year by year, the p-value of the slope was not significant $(p=0.077)$ (Table
2). For head and neck surgeries, the international benchmark (i.e., 12) was met in all years except the year 2016 to 2017 , when only 5 head and neck surgeries were performed in the pediatric population (Table 1).

Table 1: The number of surgical procedures performed during the studied years in the Western Province of Saudi Arabia in comparison to the ACGME case log system for pediatric otolaryngology

\begin{tabular}{lccccccc}
\hline \multirow{2}{*}{ Procedure domain } & \multirow{2}{*}{$\begin{array}{c}\text { ACGME } \\
\text { benchmark }\end{array}$} & \multicolumn{5}{c}{ Saudi Arabia Western Province Hospitals } \\
\cline { 3 - 8 } & $\mathbf{2 0 1 3}$ & $\mathbf{2 0 1 4}$ & $\mathbf{2 0 1 5}$ & $\mathbf{2 0 1 6}$ & $\mathbf{2 0 1 7}$ & $\mathbf{2 0 1 8}$ \\
\hline Congenital anomalies & 20 & 8 & 8 & 9 & 10 & 16 & 15 \\
Head and neck surgery & 12 & 25 & 27 & 14 & 5 & 17 & 19 \\
Otology & 30 & 7 & 4 & 3 & 2 & 1 & 6 \\
Endoscopic airway procedures & 5 & 3 & 6 & 17 & 17 & 16 & 18 \\
Open airway procedures & 8 & 5 & 6 & 13 & 11 & 12 & 11 \\
Endoscopy with intervention & 50 & 110 & 126 & 224 & 212 & 189 & 201 \\
Rhinology & 40 & 33 & 47 & 36 & 28 & 29 & 31 \\
Facial plastics & 5 & 3 & 3 & 3 & 3 & 2 & 2 \\
\hline
\end{tabular}


The average number of cases performed over the studied years (15.7) did not show a statistically significant difference from the international benchmark $(p=0.231)$ (Figure 2). The highest number of head and neck surgeries was performed during the year 2014 to 2015, when the trend of the cases was significantly downwards (slope $=-0.22042$, $\mathrm{p}=0.005$ ) (Table 2). The international benchmark for otology procedures is 30 .

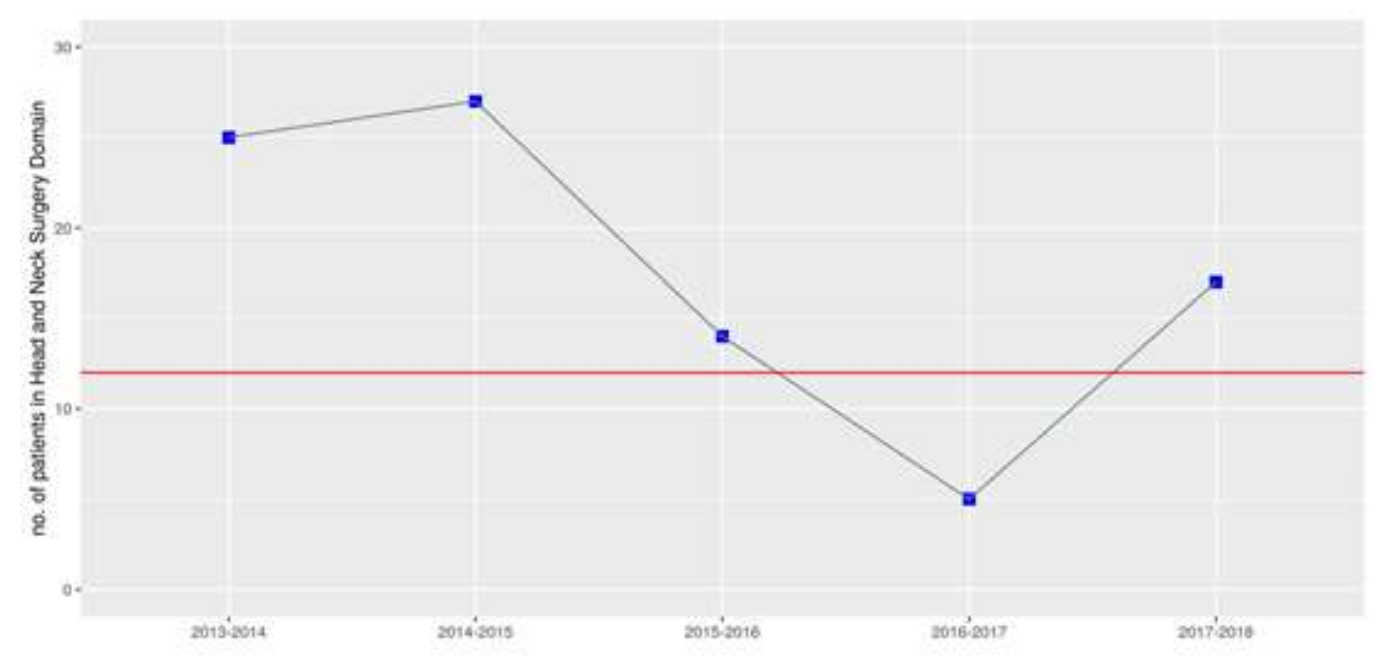

Figure 2: Number of cases performed in head and neck domain during the years 2013 to 2018 in the studied hospitals (blue line and dots) in comparison to the international benchmark (red line)

The number of cases performed yearly in the studied hospitals in Saudi Arabia was far below the benchmark throughout the studied years (Figure 3). The highest number of cases was 7 , performed during the years 2013 to
2014 (Table 1), and the number of cases significantly decreased year by year (slope $=0.44, p=0.021$ ). The lowest number encountered was a single case performed during the year 2017 to 2018 (Table 1).

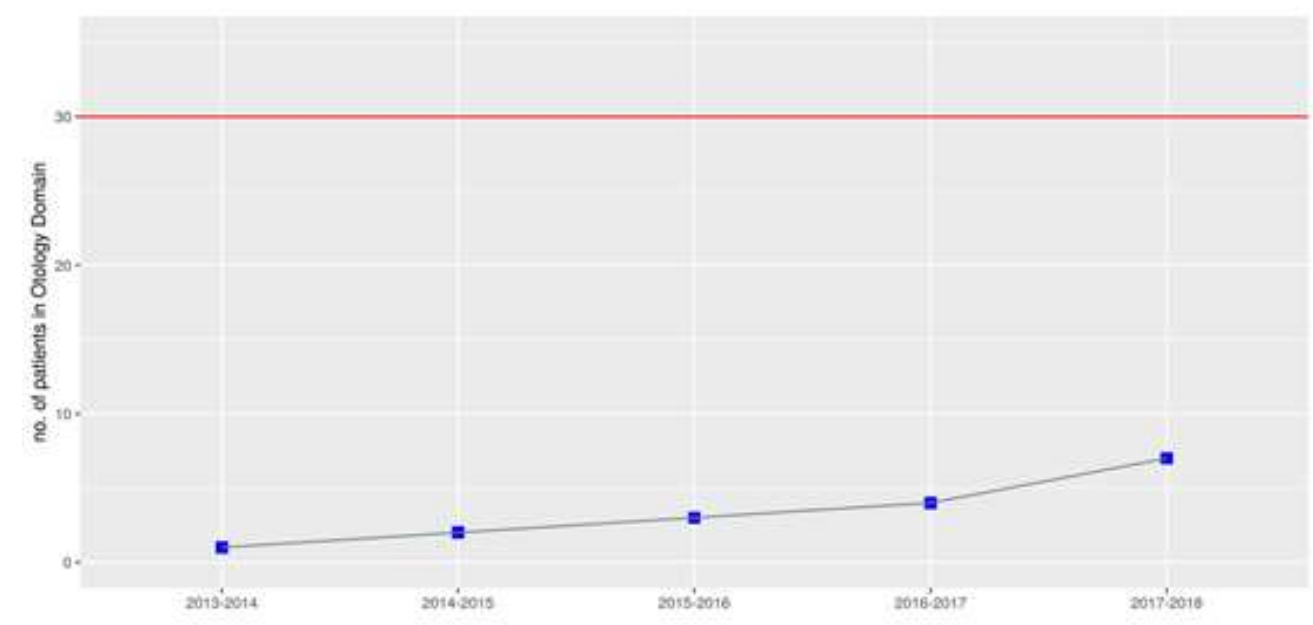

Figure 3: Number of cases performed in otology domain during the years 2013 to 2018 in the studied hospitals (blue line and dots) in comparison to the international benchmark (red line)

The average number of cases performed throughout the period was 3.4 cases per year, which is significantly lower than the international benchmark $(p<0.001)$ (Table 2). The numbers of open airway procedures performed on children at the studied hospitals are depicted in Figure 4. The international benchmark was not met during the first cycle, from 2013 to 2014, but the next years exceeded the benchmark (Table 1). 
Table 2: A comparative analysis between the average numbers of surgical procedures performed during the studied years in the Western Province of Saudi Arabia and the international benchmark, with the trend slope change over the years

\begin{tabular}{lccccc}
\hline \multicolumn{1}{c}{ Procedure domain } & $\begin{array}{c}\text { ACGME } \\
\text { benchmark }\end{array}$ & $\begin{array}{c}\text { Average } \\
\text { number }\end{array}$ & P-value & Slope & P-value \\
\hline Congenital anomalies & 20 & 10.2 & $0.003^{* *}$ & 0.1789 & 0.077 \\
Head and neck surgery & 12 & 15.7 & 0.231 & -0.22042 & $0.005^{\star *}$ \\
Otology & 30 & 3.4 & $<0.001^{* * *}$ & 0.4462 & $0.021^{*}$ \\
Closed airway (<3years) & 5 & 11.8 & 0.088 & 0.328 & $0.001^{* *}$ \\
Closed airway (>3years) & 5 & 16.8 & $<0.001^{* *}$ & -0.054 & 0.488 \\
Open airway procedures & 8 & 9.4 & 0.439 & 0.206 & 0.052 \\
Endoscopy with intervention & 50 & 172.2 & $0.006^{* *}$ & 0.143 & $<0.001^{* * *}$ \\
Rhinology & 40 & 34.6 & 0.189 & -0.078 & 0.147 \\
Facial plastics & 5 & 2.8 & $<0.001^{* *}$ & -0.072 & 0.706 \\
\hline
\end{tabular}

${ }^{*}=P<0.05,{ }^{* *}=P<0.01,{ }^{* * *}=P<0.001$

The negative sign of slope means there is a downward trend in the counts of patient

The number of cases significantly increased over the years from 2013 to 2015, then a plateau occurred from 2015 to 2017, then a slight decrease was noted in the 2017-2018 year (slope $=0.328, p=0.001$ ). The average number of cases performed yearly (11.8) was not significantly different from the international benchmark $(p=0.088)$.

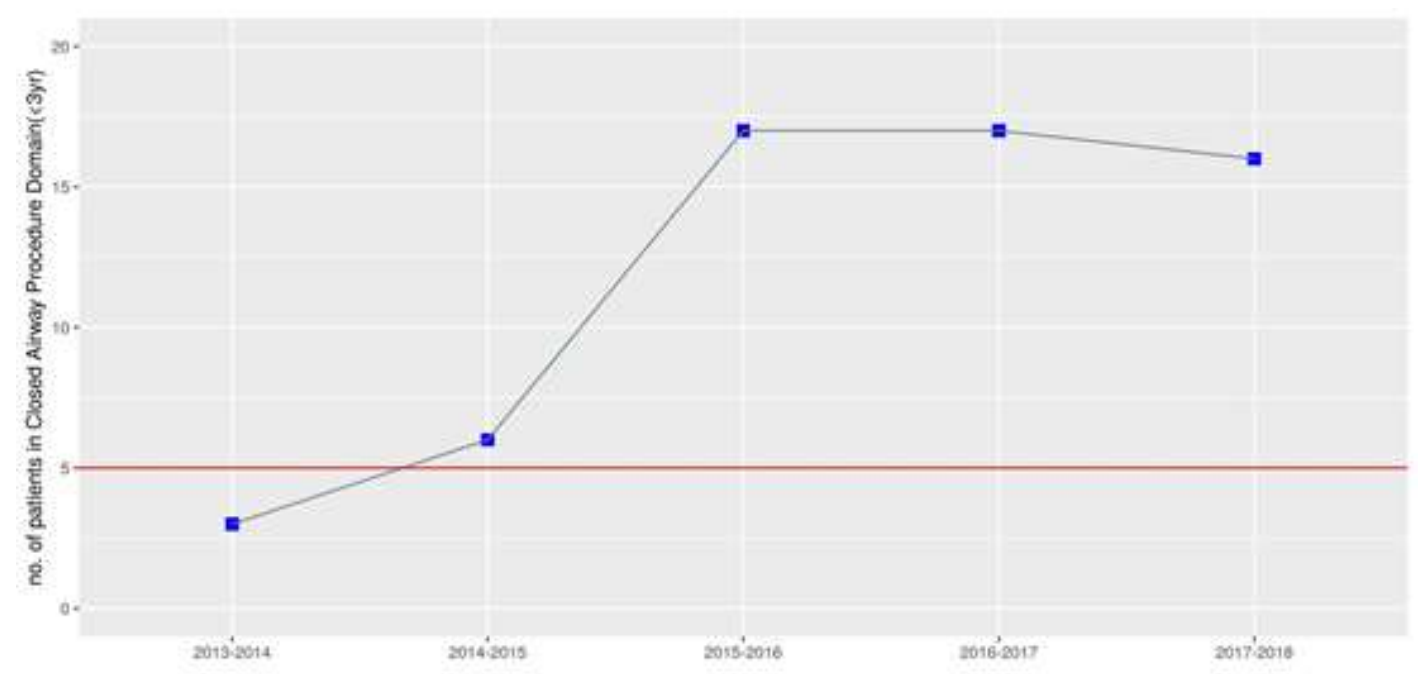

Figure 4: Number of cases performed in closed airway domain below 3 years during the years 2013 to 2018 in the studied hospitals (blue line and dots) in comparison to the international benchmark (red line)

For closed airway procedures performed in children, the number of cases performed during each of the studied years exceeded the benchmark value. The average number of cases performed was $16.8(p<0.001)$ (Table
2). The number of cases peaked during the years 2015-2016, and then the slope began to descend (Figure 5). However, the change in numbers of cases was not statistically significant (slope $=-0.054, p=0.488$ ) (Table 2). 


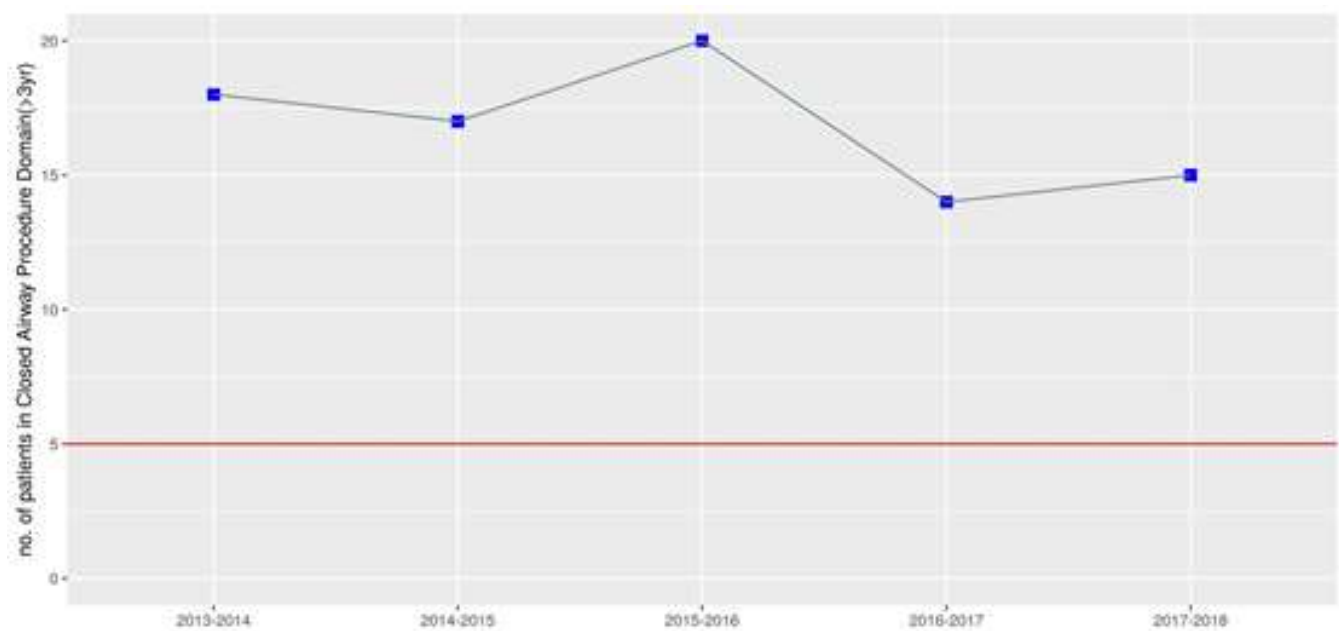

Figure 5: Number of cases performed in closed airway domain above 3 years during the years 2013 to 2018 in the studied hospitals (blue line and dots) in comparison to the international benchmark (red line)

With regards to open airway procedures, the international benchmark (8) was met from 2015 to 2018. The number of cases performed during the years 2013-2014 and 2014-2015 was slightly lower than the benchmark (Table 1). The number of annual cases increased gradually from 2013 onwards, and peaked during the years 2015-2016 (Figure 6). The numbers during the next two years remained almost stationary (slope $=0.206, p=0.052$ ). The average number of cases performed during the studied years was 9.4, which was not significantly different from the international benchmark $\quad(p=0.439) \quad($ Table 2).

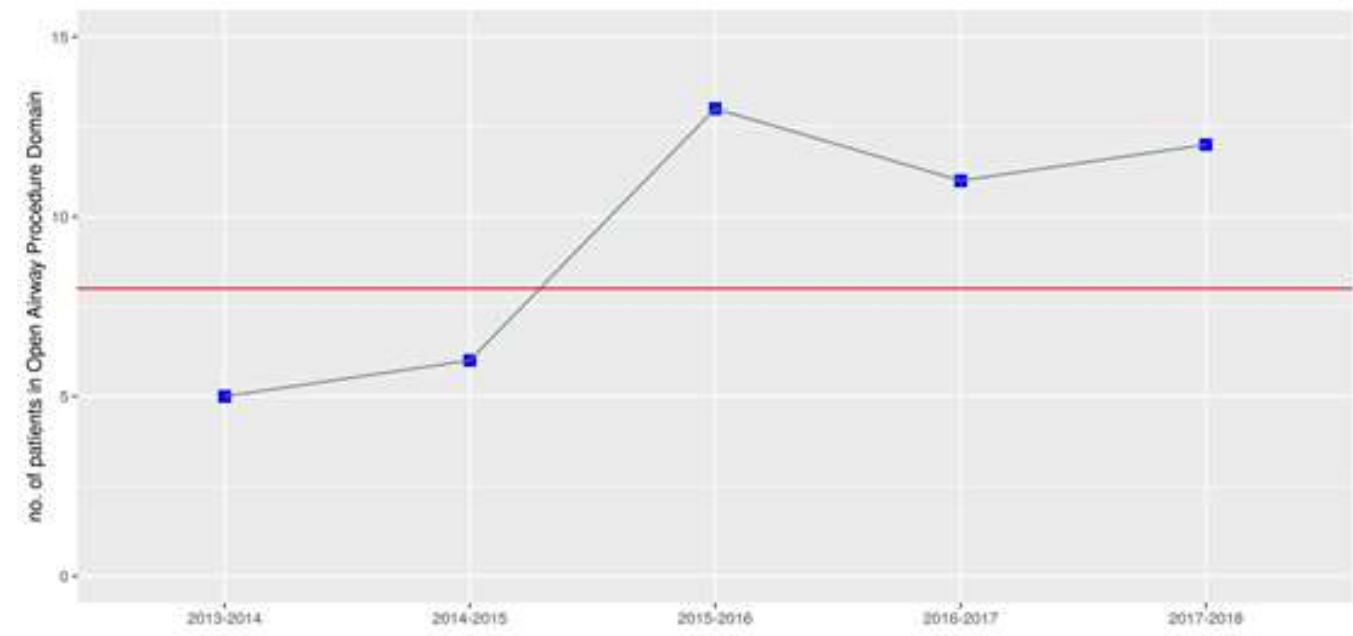

Figure 6: Number of cases performed in open airway domain during the years 2013 to 2018 in the studied hospitals (blue line and dots) in comparison to the international benchmark (red line)

The highest number of cases performed in the otolaryngology departments in the studied hospitals was encountered in the endoscopic interventions domain. The annual number of cases ranged from 110 cases in 2013-2014 to 224 cases in 2015-2016. As the international benchmark is 50 , the average number of cases performed throughout the studied years (172.2) was significantly higher than the international benchmark $(\mathrm{p}=0.006)$ (Table 2). The trend was significantly upwards (slope $=0.143, p<0.001$ ), with a peak in 20152016 years, and a slight descent later (Figure 7). 


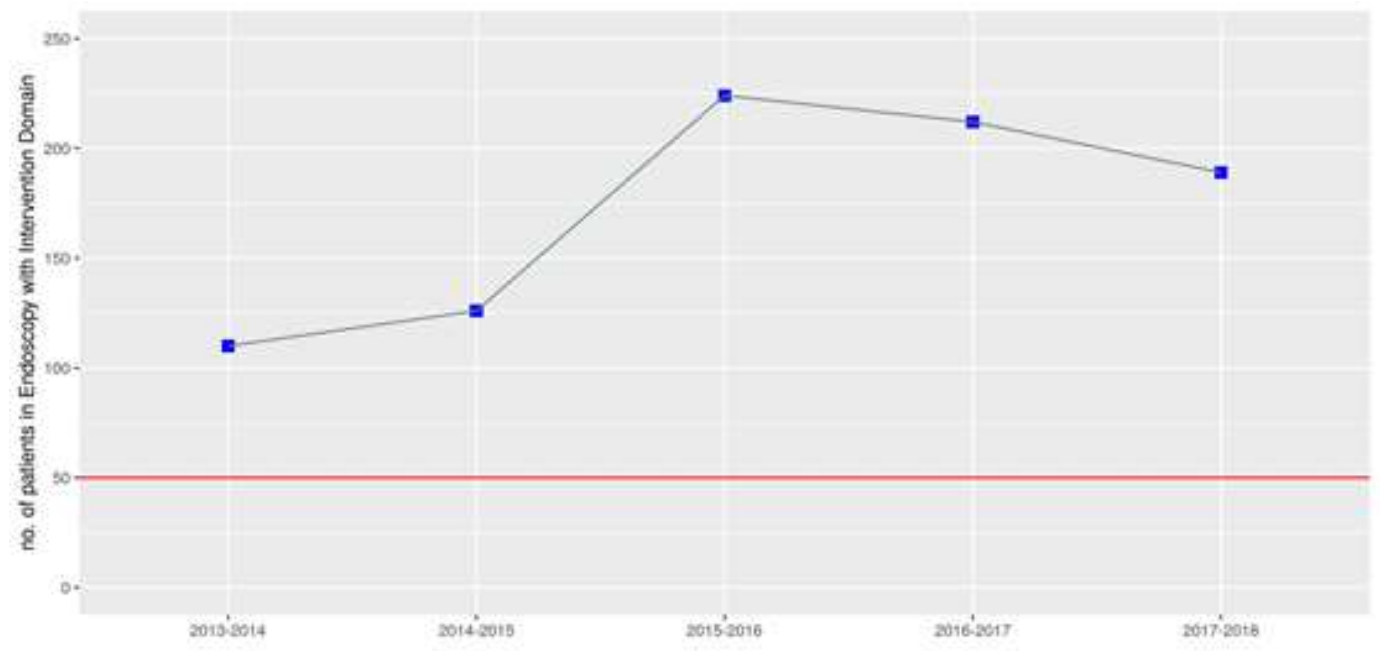

Figure 7: Number of cases performed in endoscopic interventions domain during the years 2013 to 2018 in the studied hospitals (blue line and dots) in comparison to the international benchmark (red line)

The benchmark of rhinology procedures (40) was only met during the year 2014-2015 (Table 1). The annual number of cases was below the benchmark value during the remaining years. However, the average number of cases performed throughout the years (34.6) was not significantly different from the benchmark $(p=0.147)$. The change in the number of cases throughout the years was also not statistically significant (slope $=-0.078$, $\mathrm{p}=0.147$ ) (Table 2) (Figure 8).

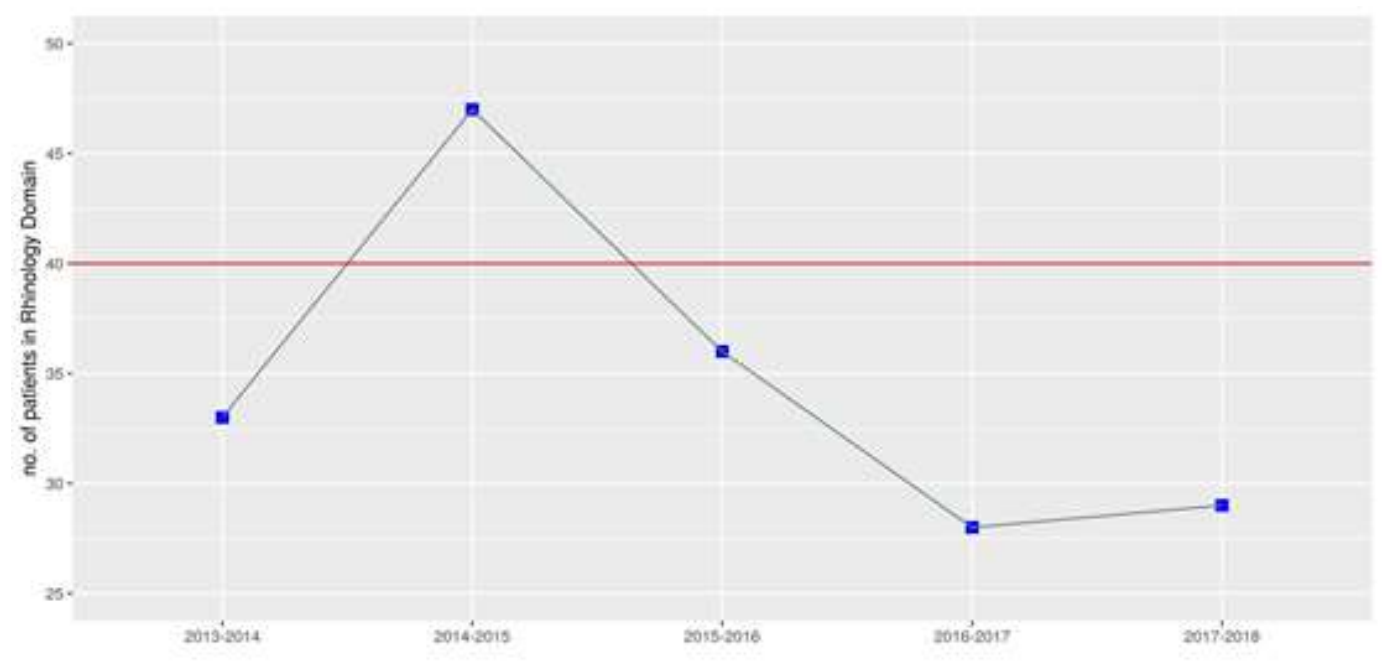

Figure 8: Number of cases performed in rhinology domain during the years 2013 to 2018 in the studied hospitals (blue line and dots) in comparison to the international benchmark (red line)

For the facial plastic domain, the annual number of cases performed was almost stationary throughout the studied years (slope=-0.072, $p=706$ ) (Table $1 \& 2$, Figure 9). The average number of cases performed was 2.8, which was significantly below the international benchmark $(5)(p<0.001)$.

\section{Discussion}

Pediatric otolaryngology is a growing medical specialty directed toward the management of complex otolaryngological diseases in pediatric age group. Pediatric patients constitute about 30 to $35 \%$ of general otolaryngology practice (Tunkel et al., 2002). 


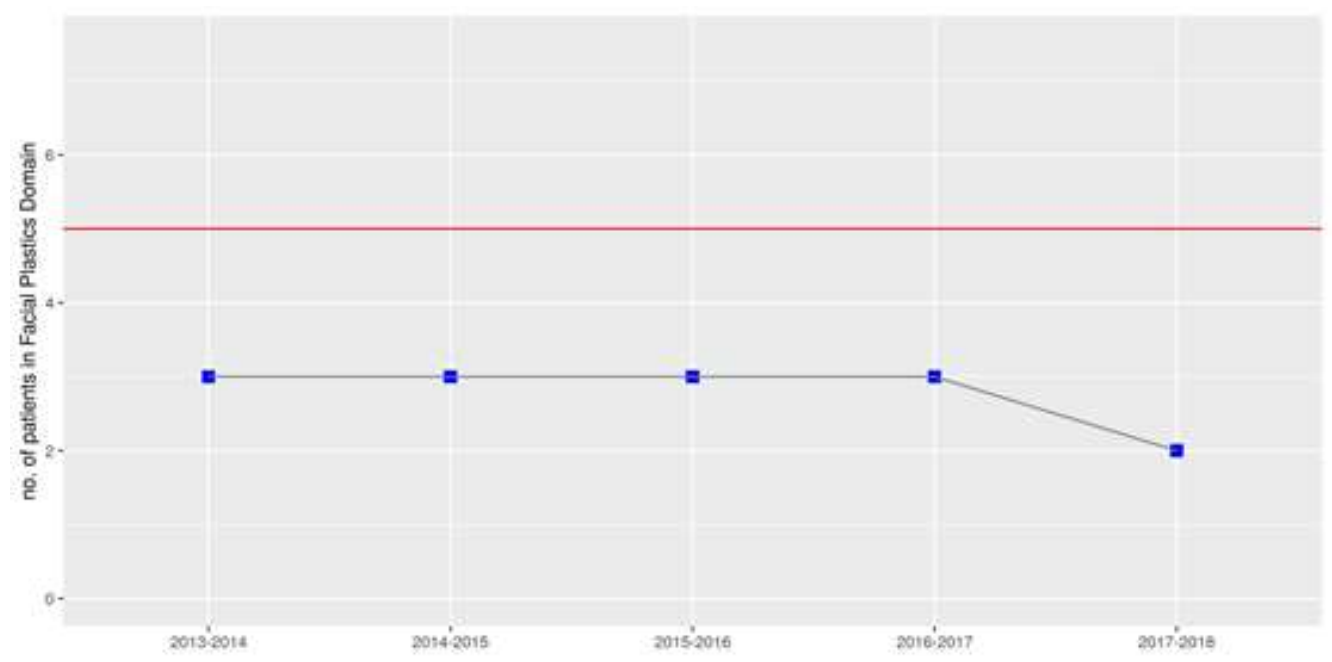

Figure 9: Number of cases performed in facial plastics domain during the years 2013 to 2018 in the studied hospitals (blue line and dots) in comparison to the international benchmark (red line)

For establishment of an efficient medical fellowship program in a country, monitoring of the program implementation and the adequate practice is fundamental. In Saudi Arabia, the pediatric otolaryngology fellowship program under the umbrella of the Saudi Council for Health Specialties started in 2013. However, no clear competency surgical load was identified.

During the past few decades, there was a shift of interest towards developing competencybased training programs, rather than durationbased training programs (Chadwick et al., 2015). Competency-based training refers to a structured approach to training that is based on achieving specific previously-determined outcomes, irrespective of the duration of the training (Burke, 2005; lobst et al., 2010; Brightwell \& Grant, 2013). It aims at assisting trainees to acquire knowledge and skills to enable them to perform specific tasks at international standards (Burke, 2005). Competency-based training is beneficial as it improves outcomes and productivity (Brightwell \& Grant, 2013). In the surgical otolaryngology field, the use of competencybased training strategies allows objective evaluation of otolaryngologists' surgical performance and subsequently identification of and response to specific learning needs (Ahmed et al., 2013). Recent trends in the accreditation of residency programs by the Accreditation Council for Graduate Medical Education (ACGME) have also focused on the implementation of objective assessments (i.e., competency-based) as part of the Outcome Project and the Next Accreditation System to determine competence in key otolaryngology procedures (Swing, 2007).

In this study, we reviewed the current surgical load in otolaryngology practice in Saudi Arabia in hospitals that have implemented the pediatric otolaryngology fellowship since 2013, and we compared our findings to international standards. Data from our study showed that the number of surgical procedures performed in certain surgical domains in the studied hospitals met the international benchmarks, while others were significantly below the international benchmarks.

The number of closed airway procedures performed, the number of endoscopic interventions and the number of head and neck surgeries were above the benchmarks in the vast majority of the studied years. The best performance was encountered in the endoscopic interventions domain as they exceeded the value of international benchmarks throughout the years, and the trend is going upwards overtime.

In contrast, the number of cases who had head and neck surgeries, despite meeting the benchmark, has decreased over time. This necessitates adequate monitoring of this surgical domain to ensure the values do not decrease in the coming years.

Procedures performed in domains such as congenital anomalies, otology, rhinology and facial plastics were usually below the benchmark throughout the studied years. The number of closed airway surgeries and open airway surgeries for children were lower than 
the benchmarks during the first few years, then the benchmark values were met, and the trends are going upwards. There are several reasons why the surgical caseload is different from international benchmark. First, we do not have a designated children's hospital in the region. Therefore, there is no streamline of cases to one place, hence the need for multiple centers to be involved in training. Second, ethnicity and environmental factors might play a role in prevalence of certain diseases than others. Lastly, there is no strict referral pattern in the country. A hospital in the central region can accept (through an online platform called "Ehalaty") a case from the western region and so forth.

However, our results showed that the fellows of the pediatric otolaryngology training program in Saudi Arabia did not meet the minimum surgical exposure necessary to graduate as a competent otolaryngologist according to the international standards in specific surgical domains (Bell et al., 2016). An important point for consideration is that the fellowship implemented in Saudi Arabia is a two-year fellowship, whilst most of the ACGME-accredited fellowship programs are one-year programs. However, some of the surgical domains covered in the fellowship do not meet the international targets. Thus, it would be recommended that the fellowship duration remain two years to enable candidates to meet the international benchmarks of the studied surgical domains. Having said that, we should consider the objective, mission and vision of our program and where the graduate will practice. So even if our program differ from international standard, it might be sufficient for the graduate to pursue a carrier in pediatric Otolaryngology in a peripheral city knowing that he/she can refer more complex cases locally, regionally, or internationally.

Several literature studies emphasized the importance of using international benchmarks and competency-based training strategies to optimize the patients' outcomes, especially in the surgery field (Ishman et al., 2010; Diaz Voss Varela et al., 2011; Chadwick et al., 2015). To the best of our knowledge, this is the first study to evaluate the otolaryngology fellowship program in Saudi Arabia and to compare it to international standards. In a similar study, however, AlEnezi et al., evaluated Saudi ophthalmology residency training programs, and compared their performance to international standards (AlEnezi et al., 2019). Knowledge of the competence level of the medical trainee and the extent to which they meet international standards would help the Saudi Council for Health Specialty to appropriately identify points of weakness and to respond to them promptly. Data from our study reflect that the competency level of otolaryngologists trained in the currently implemented fellowship program is high in certain surgical domains, but low in others. Decisions should be taken by the appropriate authorities to respond to the shortfall in the number of cases and surgical load the trainees are exposed to during the fellowship program. Yet this variation in the competency in the surgical domains might be suitable to the variety of cases seen in our country and the graduate will be competent dealing with those cases as he/she was trained for these type of surgical cases.

The main strengths of this study are that it is, to the best of our knowledge, the first study to objectively evaluate the implementation of the otolaryngology fellowship program in Saudi Arabia, and to compare it to international standards. It also included data from records over a long period of time (six years), and it covered the various surgical procedures addressed by the ACGME logbook. The main limitation of this study is that it did not evaluate the details of the training techniques of the surgical procedures, i.e., it focused only on the number (quantity) rather than the technique (quality) of the surgical procedures performed.

\section{Conclusion}

The number of surgical procedures performed in certain surgical domains (e.g., endoscopic airway procedures and the number of head and neck surgeries) in the studied hospitals meet the international benchmarks, whilst others (e.g., congenital anomalies, otology, rhinology and facial plastics) are significantly below the international benchmarks. Thus, our fellowship should stay a two-year program to allow sufficient time to meet the benchmark criteria for surgical experience, as the competency-based curriculum ensures minimal competency for the graduate when compared to a duration-based curriculum.

\section{Conflict of Interest}

The author declares no conflict of interest. 


\section{Acknowledgements}

I would like to thank Dr. Mohammed Algarni, from King Saud bin Abdulaziz University, with whom I started the fellowship in 2013.

\section{References}

Accreditation Council for Graduate Medical Education (2013). ACGME Program Requirements for Graduate Medical Education in Pediatrics. Chicago, IL: nd.

ACGME (2020) ACGME Program Requirements for Graduate Medical Education in Pediatric Otolaryngology (Subspecialty of OtolaryngologyHead and Neck Surgery).

Ahmed, A., Ishman, S.L., Laeeq, K. \& Bhatti, N.I. (2013). Assessment of Improvement of Trainee Surgical Skills in the Operating Room for Tonsillectomy. The Laryngoscope, 123, 7, pp. 1639-1644.

AlEnezi, S.H., Alfawaz, A.M., Al Owaifeer, A.M., Althiabi, S.M. \& Tabbara, K.F. (2019). Assessment of Ophthalmology Residency Programs in Saudi Arabia: A Trainee-Based Survey. Journal of Medical Education and Curricular Development, 6, p. 2382120519855060.

Baker, D.P., Gustafson, S., Beaubien, J.M., Salas, E. \& Barach, P. (2005). Medical Team Training Programs in Health Care. Agency for Healthcare Research And Quality Rockville Md.

Batalden, P., Leach, D., Swing, S., Dreyfus, H. \& Dreyfus, S. (2002). General Competencies and Accreditation in Graduate Medical Education. Health Affairs, 21, 5, pp. 103-111.

Bell, J.R., Ruch-Ross, H. \& Hotaling, A.J. (2016). Practice Patterns and Projections for the US Pediatric Otolaryngology Workforce. JAMA Otolaryngology-Head \& Neck Surgery, 142, 9, pp. 823-827.

Brightwell, A. \& Grant, J. (2013). CompetencyBased Training: Who Benefits? Postgraduate Medical Journal, 89, 1048, pp. 107-110.

Burke, J. ed. (2005). Competency Based Education and Training. Routledge.

Chadwick, K.A., Dodson, K.M., Wan, W. \& Reiter, E.R. (2015). Attainment of Surgical Competence in Otolaryngology Training. The Laryngoscope, 125, 2, pp. 331-336.
Diaz Voss Varela, D.A., Malik, M.U., Laeeq, K., Pandian, V., Brown, D.J., Weatherly, R.A., Cummings, C.W. \& Bhatti, N.I. (2011). Learning Styles in Otolaryngology Fellowships. The Laryngoscope, 121, 12, pp. 2548-2552.

GHD (2016) Saudi Arabia Demographic Survey $2016 \quad G H D x$ Available at: http://ghdx.healthdata.org/record/saudi-arabiademographic-survey-2016 [Accessed: 21/12/2019].

lobst, W.F., Sherbino, J., Cate, O.T., Richardson, D.L., Dath, D., Swing, S.R., Harris, P., Mungroo, R., Holmboe, E.S., Frank, J.R. \& International CBME Collaborators. (2010). CompetencyBased Medical Education in Postgraduate Medical Education. Medical Teacher, 32, 8, pp. 651-656.

Ishman, S.L., Brown, D.J., Boss, E.F., Skinner, M.L., Tunkel, D.E., Stavinoha, R. \& Lin, S.Y. (2010). Development and Pilot Testing of an Operative Competency Assessment Tool for Pediatric Direct Laryngoscopy and Rigid Bronchoscopy. The Laryngoscope, 120, 11, pp. 2294-2300.

Swing, S.R. (2007). The ACGME Outcome Project: Retrospective and Prospective. Medical Teacher, 29, 7, pp. 648-654.

The Pediatric Otolaryngology Milestone Project. (2015). The Accreditation Council for Graduate Medical Education and The American Board of Otolaryngology.

Tunkel, D.E., Cull, W.L., Jewett, E.A., Brotherton, S.E., Britton, C.V. \& Mulvey, H.J. (2002). Practice of Pediatric Otolaryngology: Results of the Future of Pediatric Education II Project. Archives of Otolaryngology-Head \& Neck Surgery, 128, 7, pp. 759-764.

Weaver, S.J., Rosen, M.A., Salas, E., Baum, K.D. \& King, H.B. (2010). Integrating the Science of Team Training: Guidelines for Continuing Education. Journal of Continuing Education in the Health Professions, 30, 4, pp. 208-220.

Wagner III, William, E. (2019). Using IBM® SPSS $\AA$ Statistics for Research Methods and Social Science Statistics. Sage Publications.

World Bank Statistics (2018) Population of Saudi Arabia in 2015. Available at: https://www.populationpyramid.net/saudiarabia/2018/ [Accessed: 26/12/2019]. 